\title{
Management control system, organizational learning, and firm's performance: An empirical study from developing economy
}

\author{
Rabee Shurafa *, Rapiah Bt Mohamed \\ School of Accountancy, College of Business UUM, Universiti Utara Malaysia, 06010 Sintok, Kedah, Malaysia
}

\section{ARTICLE INFO}

Article history:

Received 14 June 2016

Received in revised form

10 October 2016

Accepted 21 October 2016

\section{Keywords:}

Management control system

Levers of control

Organizational learning and

organizational performance

Developing economy

Palestine

\begin{abstract}
A B S T R A C T
Even though it is widely accepted that effective design of management control system (MCS) has the ability to stimulate organizational learning, which ultimately will enhance the organizational performance, empirical research analysis on such relationship in the context of the developing economy, in comparison to the existing literature of the developed economy, is still scarce. In particular, the influence of each of levers of control (LOC) components (belief, boundary, diagnostic, and interactive control) on the organizational learning still lacking with conflicting results. Based on a survey of 129 top managers of the Palestinian listed firms, we examine how different MCS have different influence on organizational learning and how organizational learning ultimately influences the organizational performance. The evidence suggests that neither beliefs system, nor the boundary system facilitates learning. In addition, an interactive control system also has no significant influence on organizational learning, which unlike the case of the developed economy. By contrast, diagnostic control system is the only control system that has significance influence on organizational learning. In addition, the result indicates that organizational learning has a positive influence on firm's performance. This paper contributes to stream of literature from the perspective of the developing economy and provide suggestions for potential directions of future MCS research in the context of the devolving economy.
\end{abstract}

(C) 2016 The Authors. Published by IASE. This is an open access article under the CC BY-NC-ND license (http://creativecommons.org/licenses/by-nc-nd/4.0/).

\section{Introduction}

Management control systems (MCS) represent organization's means to achieve its objectives by providing useful information to assist in decision making, planning and performance evaluation (Anthony and Govindarajan, 2007; Merchant and Van der Stede, 2011; Otley et al., 1995; Simons, 2013). By contrast, organizational learning at its basic concept means the development of prudence through the acquisition of new knowledge that has the potential to influence behavior (Sinkula, 1994; Slater and Narver, 1995), which ultimately will impact the performance.

The association between MCS and organizational learning has been examined previously to adjust control mechanisms in a way that can facilitate organizational learning for better firms performance

\footnotetext{
* Corresponding Author.

Email Address: rabeeshurafa@gmail.com (R. Shurafa)

https://doi.org/10.21833/ijaas.2016.10.013

2313-626X/@ 2016 The Authors. Published by IASE.

This is an open access article under the CC BY-NC-ND license

(http://creativecommons.org/licenses/by-nc-nd/4.0/)
}

(Bisbe and Otley, 2004; Henri, 2006; Simons, 1990; Widener, 2007). Every organization has a certain level of experience that should be converted into knowledge by exploiting MCS. The desired influence of MCS on organizational learning can be illustrated in two points. First, MCS must accumulate organizational experience; second, MCS must convert this experience into better business practice in order to build sustainable competitive advantage, since organizational learning is described as a successful management instrument applied to gain sustainable competitive advantage (Calantone, Cavusgil, and Zhao, 2002; Lonial and Carter, 2015; Lord, 2014).

In fact, Organizational experience without a future use is useless. Some organizations have years of experience, but the performance still the same or slightly difference from before, which motivated several researchers to examine the potential influence of MCS in accumulating and converting organizational historical experience into better performance. However, even though it is widely accepted that effective design of management control system (MCS) has the ability to stimulate organizational learning, which ultimately will 
enhance the organizational performance, empirical research analysis on such relationship in the context of the developing economy, in comparison to the existing literature of the developed economy, is still scarce. In particular, the influence of each of levers of control (LOC) components (belief, boundary, diagnostic, and interactive control) on the organizational learning still lacking with conflicting results. This in turn hinders the ability of MCS designers to build effective control environment that has the ability to accumulate organizational learning.

An organization must design its MCS in a way that can keep its eyes open to learn faster than its competitors in this dynamic and turbulent market environment because who can learn faster can get the competitive advantage first (De Geus, 1988; Dickson, 1992; Slater and Narver, 1995). In addition, building organizational learning can equip the organization to be more flexible in responding to the market changes in this competitive world (Day, 1994; Slater and Narver, 1995). In doing so, an organization must keep looking to learn about marketing task (Sinkula, 1994), effective and efficient MCS design (Henri, 2006; Widener, 2007), strategy formulation and competitive advantages (Simons, 1990), product innovation (McKee, 1992), strategic uncertainty (Shurafa and Mohamed, 2016), internal process development, innovation, external uncertainty among others.

Hence, in today uncertain business environment, firms must convert experience into better business practices in order to successfully survive. For that end, it is important to examine the impact of MCS on organizational learning as one of the most important ways to create an intangible competitive advantage that can enhance organizational performance, and as such, the aim of this study is to examine whether MCS in the context of the developing economy is designed with respect to facilitate learning or not. Based on Simons (1995) levers of control framework (LOC), the proposed theoretical framework is illustrated in Fig. 1.

\subsection{Overview of control systems and its sequences design}

The LOC framework consists of four sequent control systems: beliefs system, boundary system, diagnostic controls, and interactive control. The beliefs system considered (the first system) as the fundamental base that the firms has to start with in order to design the rest three systems effectively. Simons (1995) described beliefs system as "the explicit set of organizational definitions that senior managers communicate formally and reinforce systematically to provide basic values, purpose, and direction for the organization". Beliefs system used to communicate organization core values in order to inspire and motivate its members to search, initiate, create, explore, and expand their efforts in engaging in useful and appropriate actions. On the other hand, this correlates with the probability of engaging in high risk activities, which raise the need to impose some limits and restraints on activity searching behavior.

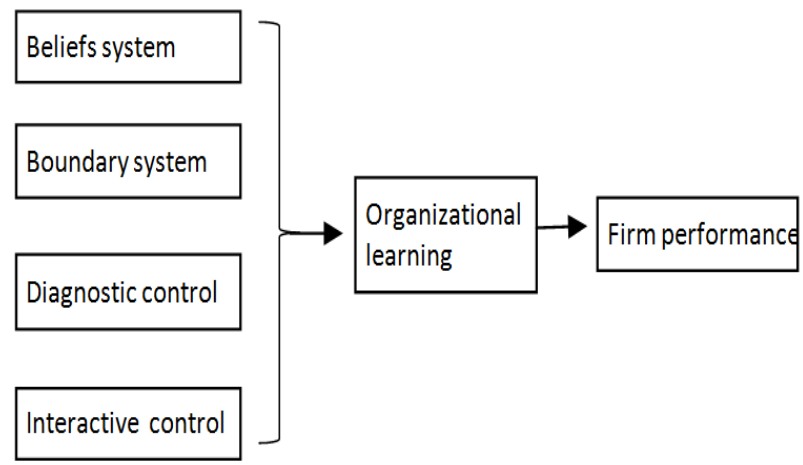

Fig. 1: Theoretical framework

This limits and constraints is the boundary system, which works in opposition manner to the beliefs system, and as such, boundary system must be design based on the beliefs system to set the most accurate limits and constraints to keep the positive energy of beliefs systems under control, and that is the starting point of the sequence design of LOC framework. A Boundary system "delineates the acceptable domain of strategic activity for organizational participants" (Simons, 1995). The idea behind the boundary system is to clearly communicate the actions and/or behavior that the organization members should avoid. Its purpose is to allow employees freedom to search, initiate, and innovate within certain pre-define areas.

In fact, both boundary and beliefs systems are similar to each other, since both systems are intended to motivate organization members to search and initiate for new ways of survival and growth; however, boundary system does so in a negative manner through its limits and constraints of behavior, whereas beliefs system does so in a positive manner through its inspiration energy (Simons, 1995). Firms often communicate its beliefs through its mission or vision statement, while its boundaries through a code of conduct.

Once, ensuring that both beliefs and boundary systems are well designed and fitting the organizational context, the sequence of LOC framework will be ready to move to the third system that responsible about measuring and communicating critical success factors that embedded in the diagnostic system. The aim of the diagnostic system is to motivate organization members to align their performance and behavior with organization objectives. It reports fundamental information that allows managers to focus their attention on monitoring critical success factors in order for the firm to attain its intended strategy. The diagnostic system considered as the backbone of the MCS, as it enables managers to benchmark organizational performance against targets. Both boundary and diagnostic systems are similar in imposing constraints on employee behavior (Simons, 2000). While diagnostic control responsible about measuring critical success factors by allowing 
managers to manage results on an exception basis, this will lead us to start thinking about forward looking by using MCS interactively.

An interactive control, as the last system in the LOC framework, allow this forward-looking as its characterized by active and frequent dialogue among top managers (Widener, 2007). Interactive control enables top managers to engage personally in monitoring the outcome of any previous systems, to stimulate search and learning for new ways to strategically position itself in a dynamic and uncertain marketplace. Simons (1995) noted that interactive control system is not a unique type of control system: "many types of control systems can be used interactively by senior managers". Choosing which control to be use interactively, depend on the strategic uncertainty level, source, type, and its possible influence. Some strategic uncertainty required beliefs system to be use interactively, while other by using boundary system interactively, whereas other uncertainties required diagnostic system to be used interactively, especially the use of performance measurements system (PMS) that embedded in diagnostic system. The above overview of MCS design by using LOC framework, obviously illustrates the logical sequence during the design process, and that mean MCS designers have to start firstly with beliefs system, following that boundary system and then diagnostic control. Once those three control systems have been designed effectively and efficiently, top managers can choose which control system to be use interactively to personally monitor strategic uncertainty (Simons, 1990). It has to be noted here, that the sequences of those systems are required during MCS design, but once the designed is done all systems are working together.

\section{Literature review and hypotheses development}

Organizational learning originates in historical experience which are then converted and encoded in routines practices (Levitt and March, 1988; Widener, 2007). Organization and based on its historical experience adopts and formalize "routines that guide behavior" (Levitt and March, 1988). According to Simons (2013), formalize routine that embedded in each of the beliefs, boundary and diagnostic system are intended to guide behavior, which will facilitate organizational learning. Simons (1995) describes the aim of beliefs system and stated, "Beliefs system is to inspire and guide organizational search and discovery", which directly influences organizational learning. Previous empirical research concludes that beliefs system has the ability to stimulate organizational learning by motivating organization members to explore, initiate, and search for new ideas and actions to reinvent organization (Marginson, 2002). Firms and based on its historical experience tend to reinvent itself in this competitive world by undertake strategic turn around through issuing new mission and vision statement.
In a study conducted by Simons (1994), he finds that firms reinvent itself by undertaken strategic turn around, based on its historical experience, issue new mission and vision statement. This new mission and vision required the development of new routines based on the organizational experience to communicate ideas and information. Beliefs system under such a case is the optimal system to achieve that, as its basic concept is to communicate organization mission and vision statement. Boundary system also motivates employees to search and explore within predefined areas (Simons, 2000). In a study investigated control components conducted in a British telecommunication companies, Marginson (2002), finds that the beliefs system opens the doors for idea, initiatives, and action. Furthermore, he finds that the boundary system motivates searching for new ideas in a predetermine domain.

The diagnostic system provides useful information, that required, to compare actual performance with the desired which is an example of single loop learning (Argyris, 1977). The diagnostic system, reports fundamental information that allows managers to focus their attention on monitoring critical success factors in order for the firm to attain its intended strategy, and as such, diagnostic control is responsible about communicating organization agenda as well as translates strategy through highlighting critical success factors (Simons, 1994, 2013). In this context, Kloot (1997), conducted two case study to examine the association between MCS and organizational learning. She concludes that performance measurement (PM) facilitate organizational learning. This is harmonious with Kaplan and Norton (1996), who emphasize the importance of PM system in communicating firm strategy to its employees. By contrast, Henri (2006) finds negative association between diagnostic and learning in the Canadian manufacturing firms, whereas Widener (2007) finds positive association between diagnostic system and organizational learning in US firms, and she reported that diagnostic system facilitates organizational learning. Organization and in order to accrued learning must be oriented to learn (Hult and Tomas, 1998). In fact, organizational culture that amenable to learn, is the key success for organization to improve its understanding of the environment over time, and as such, this will facilitate learning from historical organizational experience (Galer and Van Der Heijden, 1992). Based on the above discussion we expected that each of beliefs, boundary and diagnostic control has positive influence on organization's orientation to learning. Thus, the following hypotheses illustrate that;

H1: The beliefs system is positively associated with organization's orientation to learning.

H2: The boundary system is positively associated with organization's orientation to learning.

H3: The diagnostic control is positively associated with organization's orientation to learning. 
An interactive control system was described by Simons (1995) as a learning tool. He illustrates "these control systems stimulate search and learning, allowing new strategies to emerge as participants throughout the organization respond to perceived opportunities and threats". Thus, the main aim of this system is to inspire organizational learning. Widener (2007) highlights that an interactive control system facilitates the information process which leads to learning. Interactive use of MCS is a double loop learning system, which is a more difficult type of learning tool comparing to a single loop system (Argyris, 1977).

Interactive control system assists in designing new strategies, possibilities and ideas and also promotes a culture of curiosity and seeking behavior (Dent, 1990; Simons, 1994). Abernethy and Brownell (1999), investigated the relationship between organizational learning and interactive control system. The study empirically supported this relationship and they concluded that using a budgeting system interactively would stimulate organizational learning greater than when it is used diagnostically. Based on this discussion, the following hypothesis illustrates the relationship between interactive control system and organizational learning;

H4: The interactive control is positively associated with organization's orientation to learning.

Previous literature maintains the positive influence of organizational learning on improving performance (Bontis et al., 2002; Keskin, 2006; Lord, 2014; Slater and Narver, 1995; Zheng et al., 2010). Organizational learning is described as a successful management instrument applied to gain sustainable competitive advantage (Calantone et al., 2002; Simons, 1990). Organizational learning has also been considered to be an important long-term tool for survival and growth of an organization. Calantone et al. (2002), conducted an in depth interviews with senior executive managers to examine the impact of organizational learning on the organizational performance. The study revealed that organizational learning enhances firm's innovation, which has a direct impact on organizational performance. Tippins and Sohi (2003), empirically provides evidence regarding the positive influence of organizational learning on performance. Additional evidence was provided by (Chenhall, 2005), who finds that organizational learning has the ability to enhance delivery outcomes, which in turn enhance the performance. Henri (2006) and Widener (2007) also provides empirical support for the positive influence of learning on performance, and as such, this lead us to the following hypothesis;

H5: The firm's orientation to learn is positively associated with firm's performance.

\subsection{Research methodology}

Survey questionnaire with a cover letter was personally distributed to the top-managers of the Palestinian listed firms. We chose the top-managers as informants since they are knowledgeable about the firm's MCS. A total of 245 questionnaires were distributed in August 2015. A total of 90 questionnaires were returned. A follow up calls and emails to each of non-responding firms yield a further 47 returned questionnaires. Eight of the total respondents (137) failed to complete the questionnaires. Citing reason such as staffing constraints, contravening company, and huge amount of missing data. Consequently, a total of 129 completed questionnaires, which represent a response rate of $52.6 \%$, were used to perform data analysis. For the purpose of testing response bias, we perform t-test for early and late response as suggested by Armstrong and Overton (1977). No statically significant differences were found in the mean score on the MCS, organizational learning, and firm's performance between the early and late respondents.

\subsection{Variables measurements}

This study is based on levers of control framework, which is dependent upon the extent to which firms emphasize the use of beliefs, boundary, and diagnostic and interactive control system. Each of beliefs and boundary systems was measured by using items adopted from Widener (2007). Respondents were asked to choose their preference from a five point Likert scale ranging from 1 (strongly disagree) to 5 (strongly agree), to indicate the emphasis place on each of belief and boundary systems in their control system. The diagnostic and interactive use of MCS was measured by using items adopted from Henri (2006). Participated managers were asked to select their preference from a five point Likert ranging from 1 (Never) to 5 (Always), to indicate the emphasis they place on diagnostic and interactive system in controlling their organization. Organizational learning was measured by using four items also adopted from Henri (2006). Respondents was asked to select their preference on a five point Likert scale with reference to organizational learning ranging from 1 (strongly disagree) to 5 (strongly agree), to measure the orientation to learn.

Finally, firm's financial and non-financial performance was measured by using items adapted from (Govindarajan, 1984; Hoque and James, 2000; Widener, 2007), (Table 1). The selected instrument is conceptually consistent with Kaplan and Norton (2005), balance scorecard. Following the procedures used by previous researchers (Abernethy and Lillis, 1995; Merchant, 1984), participated managers were asked to indicate their organization's performance in comparison to their competitors by using five Likert scale ranging from 1 (very poor performance) to 5 (very good performance).

\subsection{Data analysis and research results}

Using SmartPLS 2, we analyzed the collected data. Table 1 provides outer convergent validity statistics for all items with respect to its variables. All factor 
loading of the research measurements exceed the cut-off 0.70 , which reflect the consistency between construct items (Hair et al., 2009). Similar, reliability test of this study was confirmed as all value of composite reliability exceed the recommended cutoff 0.70 and range between 0.881 to 0.941 as presented in Table 1. In addition, the recommended standard value of average variance extracted (AVE) was found to be greater than 0.50 as suggested by Fornell and Bookstein (1982), in order to ensure that the latent variable has the ability to explain more than half of the variance of its indicator on average.

Table 1: Outer model, convergent validity and composite reliability

\begin{tabular}{|c|c|c|c|c|}
\hline Construct & Items & Loading & CR & AVE \\
\hline \multirow{4}{*}{ Beliefs } & Mission statement communicates values & 0.878 & \multirow{4}{*}{0.921} & \multirow{4}{*}{0.744} \\
\hline & Top managers communicate values & 0.849 & & \\
\hline & Workforce is aware of values & 0.877 & & \\
\hline & Mission statement inspires our workforce & 0.846 & & \\
\hline \multirow{4}{*}{ Boundary } & Defines appropriate behavior & 0.890 & \multirow{4}{*}{0.893} & \multirow{4}{*}{0.676} \\
\hline & Informs about off-limits behavior & 0.770 & & \\
\hline & Communicate risks to be avoided & 0.804 & & \\
\hline & Workforce aware of code of conduct & 0.819 & & \\
\hline \multirow{4}{*}{ Diagnostic } & Track progress towards goals & 0.893 & \multirow{4}{*}{0.911} & \multirow{4}{*}{0.719} \\
\hline & Monitor results & 0.826 & & \\
\hline & Compare outcomes to expectations & 0.816 & & \\
\hline & Review key measures & 0.854 & & \\
\hline \multirow{7}{*}{ Interactive } & Enable discussion in meeting of superiors, subordinates and peers. & 0.756 & \multirow{7}{*}{0.941} & \multirow{7}{*}{0.694} \\
\hline & $\begin{array}{l}\text { Enable continual challenge and debate of underlying data, } \\
\text { assumption, and action plan. }\end{array}$ & 0.859 & & \\
\hline & provide common view of the organization. & 0.831 & & \\
\hline & Tie the organization together. & 0.860 & & \\
\hline & Enable organization to focus on critical success factors. & 0.843 & & \\
\hline & Develop a common vocabulary in the organization & 0.843 & & \\
\hline & Enable the organization to focus on common issues & 0.835 & & \\
\hline \multirow{4}{*}{ Learning } & Learning is the key to improvement & 0.856 & \multirow{4}{*}{0.881} & \multirow{4}{*}{0.650} \\
\hline & Basic values include learning as a key to improvement. & 0.823 & & \\
\hline & Once we quit learning we endanger our future. & 0.705 & & \\
\hline & Learning is viewed as an investment, not an expense. & 0.832 & & \\
\hline \multirow{7}{*}{$\begin{array}{l}\text { performan } \\
\text { ce }\end{array}$} & Overall organizational profitability. & 0.740 & \multirow{7}{*}{0.910} & \multirow{7}{*}{0.591} \\
\hline & Retun on Investment. & 0.752 & & \\
\hline & Customer satisfaction. & 0.758 & & \\
\hline & Product/ services quality. & 0.669 & & \\
\hline & Development of new products / services. & 0.819 & & \\
\hline & Developing employee competencies and skills. & 0.821 & & \\
\hline & Employee satisfaction. & 0.813 & & \\
\hline
\end{tabular}

Latent variable correlation which examining the correlations between the measures of potentially overlapping constructs appear in Table 2. The table clearly shows that the values of all square root of
AVE (Bold values) exceed the correlation with other constructs (elements in the rows and columns), which manifest the discriminant validity of this study.

Table 2: Discriminant validity- square root of AVE

\begin{tabular}{|c|c|c|c|c|c|c|}
\hline \multicolumn{2}{|c|}{ Constructs } & Be & Bo & OL & OP \\
\hline Beliefs (Be) & 0.863 & & & & & \\
\hline Boundary (Bo) & 0.770 & 0.822 & & & & \\
\hline Diagnostic (Di) & 0.641 & 0.581 & 0.848 & & & \\
\hline Interactive (In) & 0.613 & 0.647 & 0.779 & 0.833 & & \\
\hline Learning (OL) & 0.479 & 0.461 & 0.610 & 0.578 & 0.806 & \\
\hline Performance (OP) & 0.695 & 0.644 & 0.656 & 0.653 & 0.513 & 0.769 \\
\hline
\end{tabular}

As this study proofs its measurements validity and reliability, we proceed the bootstrapping approach to test research hypotheses. Path coefficient of the research hypotheses illustrated in Table 3. The first set of research hypotheses (H1-H4) predicts that, firm place more emphasis on their control systems is positively associated with organizational learning. The coefficient on the path from each of beliefs, boundary and interactive to learning $(\mathrm{H} 1, \mathrm{H} 2, \mathrm{H} 4)$ was rejected as the $\mathrm{p}$-value is greater than 0.05. In particularly, $(\mathrm{P}=0.30),(\mathrm{P}=$ 0.33), $(P=0.06)$ respectively. This concludes that firm orientation to learn is not higher when firm place emphasis on each of beliefs, boundary and interactive use of MCS. By contrast, H3 that predict firm orientation to learn is higher when emphasis place on diagnostic control was supported at $(\mathrm{p}=$ 0.01). Finally, H5 which predict positive association between organizational learning and firm's performance was supported at $(\mathrm{P}<0.01)$. 
Table 3: Path coefficient of the research hypotheses

\begin{tabular}{|c|c|c|c|c|}
\hline Relationships & Std. Beta & Std. Error & P-value & Decision \\
\hline Beliefs - $>$ Learning & 0.069 & 0.132 & 0.30 & Rejected \\
\hline Boundary -> Learning & 0.057 & 0.133 & 0.33 & Rejected \\
\hline Diagnostic - Learning & 0.365 & 0.153 & 0.01 & Supported \\
\hline Interactive -> Learning & 0.214 & 0.140 & 0.06 & Rejected \\
\hline Learning -> Performance & 0.513 & 0.071 & 0.00 & Supported* \\
\hline \multicolumn{7}{|l}{ Significant at $\mathrm{P}^{*}<0.01$}
\end{tabular}

\subsection{Discussion}

This paper sought to examine the ability of MCS, in particular, levers of control framework, in facilitating organizational learning at first, and then the impact of organizational learning on firm's performance. It was hypothesized in first set of research hypotheses (H1-H4) that, firm place more emphasis on their control systems are positively associated with organizational learning. The coefficient on the path from beliefs, to learn (H1) was rejected at $(\mathrm{P}=0.30)$. This concludes that firm orientation to learn is not higher when firm place emphasis on beliefs system. This result is contradictory with Widener (2007), who found positive association between beliefs system and orientation to learn. But it should be noted here that Widener (2007), conducted its study in a developed economy, whereas this study conducted in the developing economy to compare and understand the difference between both sides of the world regarding the possible influence of MCS on organizational learning. However, the result may also reveal the ignorance attention that given to the beliefs system in the philosophy of MCS design in the developing economy. Beliefs system represent a modern control techniques build upon employee motivation to pump the organization with required positive energy. This positive energy is the base of stimulate searching, initiating and exploring new ways of survival and growth, which for sure will assist in accumulating knowledge and experience. In fact, one of the basic requirement for organizational learning to grow, is the process of searching and initiating that embedded in beliefs system, since such process can stretch the organization to grow its knowledge and accumulate its experience, which will be later on convert to learning. By contrast, firms suffering from the absence of searching and initiating culture will also be suffering from the absence of accumulating knowledge and experience, and that for sure has negative impact on organizational learning.

As beliefs system has no impact on organizational learning, this may indicate that searching and initiating are not a fundamental part of philosophy of control system in the developing countries. In different words, beliefs system seems to be not an important part of the MCS in the developing economy, and, as such, this could explain one of the differences between developed and less developed economy regarding MCS design and use. The result of this study suggested further research to investigate whether organization in the developing economy have a culture of promoting searching and initiating that embedded in beliefs system or not, which requires deep investigation in the future research.

The coefficient on the path from boundary, to learn (H2) was also rejected at $(\mathrm{P}=0.33)$. This result is consistent with Widener (2007). Boundary system is concern about imposing limits and constraints, and as such, this kind of control system represents the traditional way of performing control. As the result of this study is consistent with result of Widener (2007) that conducted in a developed economy, this may reveal that boundary system has nothing to do with organizational learning whether in the developed or in the developing economy, since boundary system is concern to impose limits and constraints. Although it was found by Marginson (2002) that boundary system motivates searching for new ideas in a predetermined domain, this raise the need to examine the association between searching in predetermined domain and organizational learning.

Thus, companies rely heavily on the boundary system without appropriate balancing between the four controls systems (i.e. beliefs, boundary, diagnostic and interactive control), will undermine its learning growth, and that will lead to impair its ability to acquire competitive advantage as a result of its MCS design. By contrast, H3 that predict positive association between diagnostic control and organization's orientation to learning, was supported at $(\mathrm{P}=0.01)$. This result is consistent with Widener (2007) while contradictory with Henri (2006). The diagnostic system considered as the backbone of MCS, as it enables managers to benchmark organizational performance against targets. It reports information about the core success factors, which will keep the managers aware about the status of their plans and track implementation of the overall strategy through stated objectives (Simons, 2013). This process of measuring, communicating, and comparing actual result to the desired was found to have positive significant influence on organizational learning.

Comparing outcomes to the desired is the required feedback to take necessary action if there is performance deviation. Organization and under such feedback and necessary action accumulated knowledge and experience which considered as a fundamental role in facilitate its learning. Add to this, the process of preparing the diagnostic control components such as business plan, human resource plans, profit plan and budget, expenses budget, 
brand revenue among others, have positive influence on accumulating knowledge and experience, which will facilitate organizational learning.

Moving toward $\mathrm{H} 4$ that concern about the association between interactive use of MCS and learning. Path coefficient refused this relation at $(\mathrm{P}<$ 0.05). This result is consistent with Widener (2007) and incongruent with Simons (1990) and Henri (2006). Simons (1990) suggests that the structure found in formal MCS facilitate organizational learning. Widener (2007) commented on this rejected association that "interactive control system may be more organic and influence organizational learning through the formal structure of the diagnostic control system".

Nevertheless, there are two possible reasons for top managers to use MCS interactively. Firstly, to search and learn and that is the fundamental assumption behind the interactive control to enhance organizational performance through strategy renewal as was suggested by (Simons, 1990, 2013), and that perfectly has significant influence on producing and sharing information, which in turn will result in acquiring the desired knowledge and experience. This involvement of top management that is accompanied with interactive exchange of information will motivate and facilitate learning process throughout the organization (Simons, 1990, 1994, 2013). The second potential purpose of using MCS interactively by top managers in some cultures, (such as uncertainty avoidance culture) ${ }^{\dagger}$ is to ensure that the information is not manipulated in their subordinate office instead of searching and learning for strategy renewal.

As the findings of this study is incongruent with the previous study (Abernethy and Brownell, 1999; Bisbe and Otley, 2004; Henri, 2006; Simons, 1990, 1991, 2000). This may reveal that, the purpose of using MCS interactively in an uncertainty avoidance culture, such as the Arab world, is for the purpose of feeling more secure instead of searching and learning, and that has nothing to do with organizational learning. The result of the current study opens the door for further required knowledge about the purpose behind using MCS interactively in the developing economy. Furthermore, there is a need to examine the impact of national culture differences on the holistic approach of MCS such as levers of control framework.

\footnotetext{
†Uncertainty Avoidance is "the extent to which the members of a culture feel threatened by ambiguous or unknown situations" Hofstede and Hofstede (2004). Societies with high level of uncertainty avoidance are wary of their future. They believe that uncertainty is inherent in their life which represents a continuous source of threat that must be countered. In addition, people from such culture are anxious about their future (Hofstede \& Hofstede, 2004; Hofstede et al., 2010). Therefore, they adhere to strict laws, rules, security, safety and believe in absolute truth as the only way to confront uncertainty. Furthermore, autocratic style of management and control will be found in their organizations as well as less participation with a preference for rule-based (Hofstede \& Bond, 1988). An example of such societies includes Arab countries, Taiwan, Greece, and France.
}

The last hypothesis H5 that was predicted positive association between organizational learning and firm's performance was supported at $(\mathrm{P}<0.01)$. This result is in harmonious with previous studies such as (García-Morales et al., 2012; Hussein et al., 2014; Jain and Moreno, 2015; Lord, 2014; Noruzy et al., 2013), whom empirically supported the positive significance association between organizational learning and organizational performance. This result supports the claim of the importance of resource based view theory (RBV), on enhancing organizational performance by creating intangible competitive advantage that ultimately will improve the performance (Baker and Sinkula, 1999; JiménezJiménez and Sanz-Valle, 2011; Lonial and Carter, 2015; Lord, 2014; Santos-Vijande et al., 2012).

Accordingly, organizational learning considered as a critical antecedent factor of firm's performance. This finding suggests that the companies, which plan to enhance its performance by building competitive advantage, need to start building their learning first. Indeed, the direct influence of the organizational learning can be seen on the organizational innovation capabilities that will lead to better performance (Turner and Pennington, 2015). Therefore, organizational learning is described as a successful management instrument applied to gain sustainable competitive advantage (Calantone et al., 2002; Fraj et al., 2015; Simons, 1990). Thus, organizational learning can lead to higher performance growth, and as such, learning has also been considered to be an important long-term tool of survival and growth.

\section{Limitation and suggestion for future work}

Despite the contributions have been done by conducting this research regarding the association between MCS and organizational learning and the outcome of this relation on firm's performance, as is always the case in doing social research work, the current study has some limitations that have to be reported for the benefit of future research. First, this study conducted in one developing country (Palestine). It is possible that companies in other settings differ from their Palestinian counterparts. This may be so because of the size of the Palestinian economy, the politico-economic uncertainty and nature of market competition, economic policies or structures, national culture, legal and regulatory constraints that might differ among developing countries. These possible differences may restrict generalizing the result beyond the context of Palestine to encompass the whole developing countries.

Relying on collecting data from one developing country impede the possibility of making useful comparison, regarding the impact of MCS on organizational learning between developed and developing economy. Therefore, it's beneficial for future research to repeat the study in different developing countries to come up with more result for the purpose of making useful and comprehensive 
comparison between both sides of the world. Furthermore, collecting data from more than one developing country will assist to examine whether this side of the world, has same preferences regarding MCS design as well as its possible outcome (e.g., organizational learning) or there is difference among them.

The second limitation of generalizing the result of this study beyond the Palestinian context, is that Palestine dominated by long-term political uncertainty since decades, and that may influence the philosophy of MCS design (Shurafa and Mohamed, 2016). Hence, future research is suggested to examine the possible influence of such long-term uncertainty on MCS design, in particular on levers of control framework as it is representing the holistic approach of control system.

Third, Firm's performance was measured by using a survey questionnaire, asking the managers to self-assess their organization's performance; such self-assessment may introduce bias in the performance measure. Regardless of these limitation, the findings reported in this study and further research would help improve our understanding regarding the possible influence of MCS in facilitate organizational learning.

\section{Conclusion}

The primary aim of this study is to test hypotheses and provide evidence on the relationship between levers of control as the holistic approach of MCS, and organizational learning and the outcome of this relation on firm's performance. The purpose behind examine these relationships is to get a more in-depth understanding of the role of each of belief, boundary, diagnostic, and interactive control in facilitating organizational learning in order to build sustainable competitive advantages, which in turn will sustain performance growth in this competitive world.

The findings show that only the diagnostic control system has significant influence on organizational learning. Although diagnostic control system is considered as the backbone of MCS, the rejected influence between each of belief, boundary, and interactive control raise an important question regarding MCS design in the developing countries and whether these companies design their control with respect to build their organizational learning or not. Indeed, in depth research is required to understand how companies from developing economy design its MCS. In depth understanding might assist us recognize the possible reasons behind the better performance of the firms from the developed countries on their counterparts from the developing countries, which could be as a result of ineffective MCS in the developing economy.

In conclusion, the findings also show significant association between organizational learning and performance, which should motivate the firms to give more attention to design effective MCS that has the ability to stimulate organizational learning for the purpose of building competitive advantage to sustain growth and development.

\section{References}

Abernethy MA and Brownell P (1999). The role of budgets in organizations facing strategic change: an exploratory study. Accounting, Organizations and Society, 24(3): 189-204.

Abernethy MA and Lillis AM (1995). The impact of manufacturing flexibility on management control system design. Accounting, Organizations and Society, 20(4): 241-258.

Anthony R and Govindarajan V (2007). Management Control Systems. McGraw-Hill, Boston, USA.

Argyris C (1977). Organizational learning and management information systems. Accounting, Organizations and Society, 2(2): 113-123.

Armstrong JS and Overton TS (1977). Estimating nonresponse bias in mail surveys. Journal of Marketing Research, 14(8): 396-402.

Baker WE and Sinkula JM (1999). The synergistic effect of market orientation and learning orientation on organizational performance. Journal of the Academy of Marketing Science, 27(4): 411-427.

Bisbe J and Otley D (2004). The effects of the interactive use of management control systems on product innovation. Accounting, Organizations and Society, 29(8): 709-737.

Bontis N, Crossan MM and Hulland J (2002). Managing an organizational learning system by aligning stocks and flows. Journal of Management Studies, 39(4): 437-469.

Calantone RJ, Cavusgil ST and Zhao Y (2002). Learning orientation, firm innovation capability, and firm performance. Industrial Marketing Management, 31(6): 515-524.

Chenhall RH (2005). Integrative strategic performance measurement systems, strategic alignment of manufacturing, learning and strategic outcomes: an exploratory study. Accounting, Organizations and Society, 30(5): 395-422.

Day GS (1994). The capabilities of market-driven organizations. The Journal of Marketing, 58(4): 37-52.

De Geus AP (1988). Planning as learning. Harvard Business Review, 66(2): 70-74.

Dent JF (1990). Strategy, organization and control: some possibilities for accounting research. Accounting, Organizations and Society, 15(1): 325.

Dickson PR (1992). Toward a general theory of competitive rationality. The Journal of Marketing, 56(1): 69-83. 
Fornell C and Bookstein FL (1982). Two structural equation models: LISREL and PLS applied to consumer exit-voice theory. Journal of Marketing Research, 19(4): 440-452.

Fraj E, Matute J and Melero I (2015). Environmental strategies and organizational competitiveness in the hotel industry: The role of learning and innovation as determinants of environmental success. Tourism Management, 46: 30-42.

Galer G and Van Der Heijden K (1992). The learning organization: how planners create organizational learning. Marketing Intelligence and Planning, 10(6): 5-12.

García-Morales VJ, Jiménez-Barrionuevo MM and Gutiérrez-Gutiérrez L (2012). Transformational leadership influence on organizational performance through organizational learning and innovation. Journal of Business Research, 65(7): 1040-1050.

Govindarajan V (1984). Appropriateness of accounting data in performance evaluation: an empirical examination of environmental uncertainty as an intervening variable. Accounting, Organizations and Society, 9(2): 125135.

Hair JF, Black WC, Babin BJ and Anderson RE (2009). Multivariate data analysis. $7^{\text {th }}$ Edition, Pearson Prentice Hall, New Jersey, USA.

Henri JF (2006). Management control systems and strategy: a resource-based perspective. Accounting, Organizations and Society, 31(6): 529-558.

Hofstede G and Bond M (1988). The Confucius connection: From cultural roots to economic growth. Organizational Dynamics, 16(4): 5-21.

Hofstede G and Hofstede GJ (2004). Cultures and organizations: Software for the mind. $2^{\text {nd }}$ Edition, McGraw-Hill, London, UK.

Hofstede G, Hofstede GJ and Minkov M (2010). Cultures and Organizations: Software of the Mind. $3^{\text {rd }}$ Edition, McGraw-Hill Education, London, UK.

Hoque $\mathrm{Z}$ and James W (2000). Linking balanced scorecard measures to size and market factors: Impact on organizational performance. Journal of Management Accounting Research, 12(1): 1-17.

Hult $T$ and Tomas $M$ (1998). Managing the international strategic sourcing process as a market-driven organizational learning system. Decision Sciences, 29(1): 193-216.

Hussein N, Mohamad A, Noordin F and Ishak NA (2014). Learning organization and its effect on organizational performance and organizational innovativeness: A proposed framework for Malaysian Public Institutions of Higher Education. Procedia-Social and Behavioral Sciences, 130: 299-304.
Jain AK and Moreno A (2015). Organizational learning, knowledge management practices and firm's performance: an empirical study of a heavy engineering firm in India. The Learning Organization, 22(1): 14-39.

Jiménez-Jiménez D and Sanz-Valle R (2011). Innovation, organizational learning, and performance. Journal of Business Research, 64(4): 408-417.

Kaplan R and Norton D (2005). The balanced scorecard: measures that drive performance. Harvard Business Review, 83(7): 172-180.

Kaplan RS and Norton DP (1996). The balanced scorecard: Translating strategy into action. $1^{\text {st }}$ Edition, Harvard Business Review Press, Brighton, USA.

Keskin H (2006). Market orientation, learning orientation, and innovation capabilities in SMEs: An extended model. European Journal of Innovation Management, 9(4): 396-417.

Kloot L (1997). Organizational learning and management control systems: Responding to environmental change. Management Accounting Research, 8(1): 47-73.

Levitt B and March JG (1988). Organizational learning. Annual Review of Sociology, 14: 319340.

Lonial SC and Carter RE (2015). The impact of organizational orientations on medium and small firm performance: A resource-based perspective. Journal of Small Business Management, 53(1): 94113.

Lord M (2014). University endowment committees: how a learning orientation and knowledge factors contribute to portfolio diversification and performance. The European Journal of Finance, 22(8-9): 1-25.

Marginson DE (2002). Management control systems and their effects on strategy formation at middlemanagement levels: evidence from a UK organization. Strategic Management Journal, 23(11): 1019-1031.

McKee D (1992). An organizational learning approach to product innovation. Journal of Product Innovation Management, 9(3): 232-245.

Merchant KA (1984). Influences on departmental budgeting: an empirical examination of a contingency model. Accounting, Organizations and Society, 9(3): 291-307.

Merchant KA and Van der Stede WA (2011). Management control systems: performance measurement, evaluation and incentives. $3^{\text {rd }}$ Edition, Pearson Prentice Hall, New Jersey, USA.

Noruzy A, Dalfard VM, Azhdari B, Nazari-Shirkouhi S and Rezazadeh A (2013). Relations between transformational leadership, organizational 
learning, knowledge management, organizational innovation, and organizational performance: an empirical investigation of manufacturing firms. The International Journal of Advanced Manufacturing Technology, 64(5-8): 1073-1085.

Otley D, Broadbent J and Berry A (1995). Research in management control: An overview of its development. British Journal of Management, 6(1): S31-S44.

Santos-Vijande ML, López-Sánchez JÁ and Trespalacios JA (2012). How organizational learning affects a firm's flexibility, competitive strategy, and performance. Journal of Business Research, 65(8): 1079-1089.

Shurafa R and Mohamed R (2016). Management control system under the pressure of strategic uncertainty: The case of the Arab world. Australian Journal of Basic and Applied Sciences, 10(7): 130-134.

Simons R (1990). The role of management control systems in creating competitive advantage: New perspectives. Accounting, Organizations and Society, 15(1): 127-143.

Simons R (1991). Strategic orientation and top management attention to control systems. Strategic Management Journal, 12(1): 49-62.

Simons R (1994). How new top managers use control systems as levers of strategic renewal. Strategic Management Journal, 15(3): 169-189.

Simons R (1995). Levers of control-how managers use innovative control systems to drive strategic renewal. Harward Business School Press, Boston, USA.
Simons R (2000). Performance measurement and control systems for implementing strategy. Pearson Prentice Hall, New Jersey, USA.

Simons R (2013). Levers of control: How managers use innovative control systems to drive strategic renewal. Harvard Business Review Press, Brighton, USA.

Sinkula JM (1994). Market information processing and organizational learning. The Journal of Marketing, 58 (1): 35-45.

Slater SF and Narver JC (1995). Market orientation and the learning organization. Journal of Marketing, 59(3): 63-74.

Tippins MJ and Sohi RS (2003). IT competency and firm performance: is organizational learning a missing link?. Strategic management journal, 24(8): 745-761.

Turner T and Pennington W (2015). Organizational networks and the process of corporate entrepreneurship: how the motivation, opportunity, and ability to act affect firm knowledge, learning, and innovation. Small Business Economics, 45(2): 447-463.

Widener SK (2007). An empirical analysis of the levers of control framework. Accounting, Organizations and Society, 32(7): 757-788.

Zheng W, Yang B and McLean GN (2010). Linking organizational culture, structure, strategy, and organizational effectiveness: Mediating role of knowledge management. Journal of Business Research, 63(7): 763-771. 